\title{
PROCESS PARAMETERS, ORIENTATION, AND FUNCTIONAL PROPERTIES OF MELT-PROCESSED BULK Y-Ba-Cu-O SUPERCONDUCTORS*
}

I. V. Zakharchenko, K. M. Terryll, and K.V. Rao
Department of Condensed Matter Physics
Royal Institute of Technology
Stockholm, Sweden

and

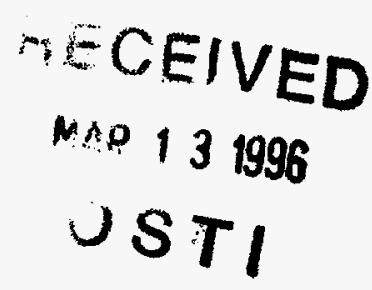

\author{
U. Balachandran \\ Energy Technology Division \\ Argonne National Laboratory \\ Argonne, IL 60439 U.S.A.
}

\section{March 1995}

The submitted manuscript has been authored
by a contractor of the U.S. Governmen:
under contract No. W-31-109-ENG-38.
Accordingly. the U. S. Government retains a
nonexclusive. royalty-free license to publish
or reproduce the published form of this
contribution, or allow others to do so, for
$U$. S. Government purposes.

U. S. Government purposes.

\begin{abstract}
DISCLAIMER
This report was prepared as an account of work sponsored by an agency of the United States Government. Neither the United States Government nor any agency thereof, nor any of their employees, makes any warranty, express or implied, or assumes any legal liability or responsibility for the accuracy, completeness, or usefulness of any information, apparatus, product, or process disclosed, or represents that its use would not infringe privately owned rights. Reference herein to any specific commercial product, process, or service by trade name, trademark, manufacturer, or otherwise does not necessarily constitute or imply its endorsement, recommendation, or favoring by the United States Government or any agency thereof. The views and opinions of authors expressed herein do not necessarily state or reflect those of the United States Government or any agency thereof.
\end{abstract}

*Work at the Royal Institute of Technology is supported by the Swedish Funding Agencies NUTEK and NFR. Work at ANL is supported by the U.S. Department of Energy, Energy Efficiency and Renewable Energy, as part of a program to develop electric power technology, under Contract W-31-109-Eng38. 


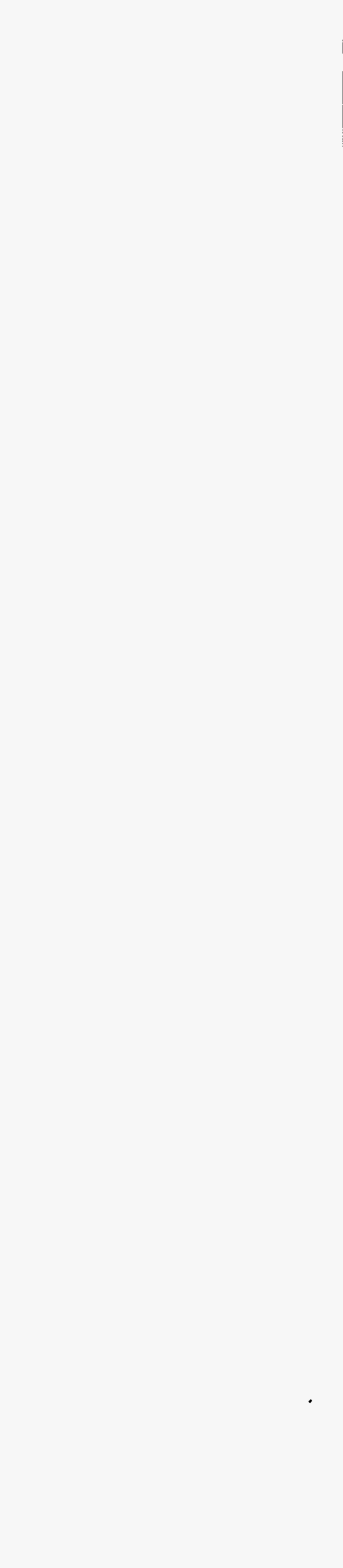

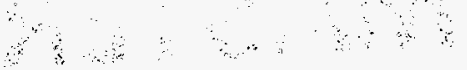


PROCESS PARAMETERS, ORIENTATION, AND FUNCTIONAL PROPERTIES OF MELT-PROCESSED BULK Y-Ba-Cu-O SUPERCONDUCTORS

I. V. Zakharchenko, K. M. Terryll, and K.V. Rao

Department of Condensed Matter Physics

Royal Institute of Technology

Stockholm. Sweden

and

U. Balachandran

Energy Technology Division

Argonne National Laboratory

Argonne, IL 60439 U.S.A.

\begin{abstract}
This study compared the microstructure, texturing, and functional properties (critical currents) of $\mathrm{YBa}_{2} \mathrm{Cu}_{3} \mathrm{O}_{7-\mathrm{x}}$-based bulk pellets that were prepared by the quench-melt-growth-process (QMGP), melt-textured growth (MTG), and conventional solid-state reaction (SSR) approaches. Using two $\mathrm{X}$-ray diffraction (XRD) methods, $\theta-2 \theta$, and rocking curves, we found that the individual grains of two melt-processed pellets exhibited remarkable preferred orientational alignment (best rocking curve width $=3.2^{\circ}$ ). However, the direction of the preferred orientation among the grains was random. Among the three types of bulk materials studied, the QMGP sample was found to have the best $J_{c}$ values, $\approx 4500 \mathrm{~A} / \mathrm{cm}^{2}$ at $77 \mathrm{~K}$ in a field of $2 \mathrm{kG}$, as determined from SQUID magnetic data.
\end{abstract}

\title{
INTRODUCTION
}

Since its discovery in $1987, \mathrm{YBa}_{2} \mathrm{Cu}_{3} \mathrm{O}_{7-\mathrm{x}}$ has probably been the most extensively studied superconductor [1]. $\mathrm{YBa}_{2} \mathrm{Cu}_{3} \mathrm{O}_{7-\mathrm{x}}$ single crystals exhibit 
better homogeneity, transition temperature $\left(T_{c}\right)$, critical current density $\left(J_{c}\right)$, and preferred orientation than bulk samples. Usually, in the bulk ceramic superconductors, $J_{c}$ is orders of magnitude lower $\left(150-600 \mathrm{~A} / \mathrm{cm}^{2}\right.$ at $77 \mathrm{~K}$ ) than it is in a single crystal $\left(5 \times 10^{6} \mathrm{~A} / \mathrm{cm}^{2}\right.$ at $\left.77 \mathrm{~K}\right)[2,3]$. Weak links are typical for bulk superconductors and include dislocations, impurities, and high-angle grain boundaries that often hinder the possibilities of obtaining higher $J_{c}$ values. Generally, the melt-textured-growth (MTG) approach is to heat bulk $\mathrm{YBa}_{2} \mathrm{Cu}_{3} \mathrm{O}_{7-\mathrm{x}}(123)$ above its peritectic temperature $\left(1010^{\circ} \mathrm{C}\right)$ for a few minutes and then rapidly cool the pellets to different temperature plateaus, followed by slow cooling to $\approx 950^{\circ} \mathrm{C}$. The quench-melt-growth process (QMGP) is very similar to the MTG approach, except for the high-temperature $\left(1300^{\circ} \mathrm{C}\right)$ quenching step that is included at the beginning to ensure that the $\mathrm{Y}_{2} \mathrm{BaCuO}_{5}$ (211) phase is finely distributed.

The sequence of events during premelting and subsequent solidification have been extensively studied by Rodriguez et al. [4] and Golden et al. [5]. The high-temperature reactions of 123 showed the development of a phase, tentatively identified as 211 , along with the 123 phase at temperatures between 700 and $940^{\circ} \mathrm{C}$. Golden et al. [5], found that even materials quenched from temperatures as low as $950^{\circ} \mathrm{C}$ contained a phase mixture. This indicated the presence of a metastable liquid at temperatures of $950^{\circ} \mathrm{C}$ and above. The end product of MTG usually contains mixed phases of $211, \mathrm{BaCuO}_{2}$, and $\mathrm{CuO}$. Some evidence indicates that the 123 phase does not nucleate at 211 particles in $\mathrm{Y}$-deficient liquid [6].

A very dense and preferentially aligned microstructure obtained by melt processing can give rise to dramatically improved $J_{c}$, and significantly reduced 
field dependence. In the MTG polycrystalline $123, J_{\mathrm{C}}$ is usually $\approx 5000 \mathrm{~A} / \mathrm{cm}^{2}$, at $\mathrm{H}=0$ and $\mathrm{T}=77 \mathrm{~K}$.

In this detailed investigation, we have studied, for the first time, the preferred orientation of each grain in melt-processed 123 samples. We show that the melt-processed samples exhibit preferred orientations comparable to those in single crystals.

\section{EXPERIMENTAL METHOD}

The powders $\mathrm{Y}_{2} \mathrm{O}_{3}, \mathrm{BaCO}_{3}$, and $\mathrm{CuO}$ were mixed, ground, and heated in a tube furnace with flowing oxygen gas. The total oxygen pressure inside the furnace was maintained at $3.3 \mathrm{~mm} \mathrm{Hg}$ with a vacuum pump. During cooling, the pressure inside the furnace was raised to ambient pressure at $850^{\circ} \mathrm{C}$, and further cooling was continued in the flowing oxygen at ambient pressure [7].

The first of the three pellets was made by QMGP. Approximately $20 \mathrm{~g}$ of the above-described powder was quenched from $1350^{\circ} \mathrm{C}$. The powder was then pressed into $\approx 3-\mathrm{cm}$-diameter pellets under $50 \mathrm{MPa}$ pressure. It was then melt processed in air according to the following scheme: the pellet was ramped from $25^{\circ} \mathrm{C}$ at the rate of $200^{\circ} \mathrm{C} / \mathrm{h}$ to $1040^{\circ} \mathrm{C}$. Then it was ramped at a rate of $60^{\circ} \mathrm{C} / \mathrm{h}$ to $1060^{\circ} \mathrm{C}$, and held for $1 \mathrm{~h}$. It was cooled at $500^{\circ} \mathrm{C} / \mathrm{h}$ to $1000^{\circ} \mathrm{C}$, at $3^{\circ} \mathrm{C} / \mathrm{h}$ to $900^{\circ} \mathrm{C}$, and finally, at $60^{\circ} \mathrm{C} / \mathrm{h}$ to $25^{\circ} \mathrm{C}$. The pellet was then oxygenated at $\approx 550^{\circ} \mathrm{C}$ for $24 \mathrm{~h}$ in $100 \%$ oxygen gas and slowly cooled to room temperature.

The MTG pellet was produced with the same powder and procedure used for the QMGP pellet, except that the powder was not quenched from $1350^{\circ} \mathrm{C}$. All melting and cooling experiments were carried out in air under ambient conditions. Oxygenation was performed in $100 \%$ oxygen gas flow. 
The third. and conventional, pellet was made by solid-state reaction (SSR) from the same $\mathrm{YBa}_{2} \mathrm{Cu}_{3} \mathrm{O}_{7}$ precursor powder used for the others. The pellets were sintered at $945^{\circ} \mathrm{C}$ for $10 \mathrm{~h}$, oxygenated at $\approx 550^{\circ} \mathrm{C}$, and slow cooled in $100 \%$ oxygen.

\section{RESULTS AND DISCUSSION}

The specimens for X-ray and magnetic characterization were cut in the form of cubes or identical parallelepipeds from three bulk samples, identified as MTG, QMGP, and SSR. X-ray diffraction measurements were carried out on all of the faces of the specimens as shown in Figs. 1 and 2. The rather narrow peaks in the X-ray diffraction patterns (Fig. 1), and their high intensities, suggest that rather large grains are present in the MTG pellet. The degree of orientation in the QMGP pellet has been investigated in detail with rocking curve measurements similar to the ones shown in Fig. 2 for MTG.

The MTG sample exhibited excellent preferred orientation, as indicated by a thorough analysis of the data obtained at each face of the cut sample (Figs: 1 and 2). The best preferred orientation was determined to be on Side $\mathrm{C}$ of the rectangular piece and this is shown in Fig. 2 by the rocking curve distribution width, full width half maximum (FWHM), of $3.2^{\circ}$. This outstanding preferred grain orientation is comparable to that which is usually seen only in $\mathrm{YBa}_{2} \mathrm{Cu}_{3} \mathrm{O}_{7-\mathrm{x}}$ single crystals with FWHM $\approx 8-10^{\circ}$ [8]. Bulk $\mathrm{YBa}_{2} \mathrm{Cu}_{3} \mathrm{O}_{7-\mathrm{x}}$ commonly exhibits a preferred orientation in the range of $20-30^{\circ}$ [8]. The $\theta-2 \theta$ $\mathrm{X}$-ray diffraction pattern for MTG shows that the c-axis preferred orientation is in the 001 direction. However, this preferred orientation differs in its direction on each side of this small piece with dimensions $3.0 \times 3.2 \times 5.1 \mathrm{~mm}$. 
On side $A$, which is parallel to side $C$. the preferred orientation is in two directions, corresponding to the 110 and 220 planes (Fig. 2). The similar preferred orientation occurs on parallel sides $D$ and $B$. On side $D$, the $\theta-2 \theta$ and rocking curve XRDs show that the preferred orientation in the 200 plane has a narrow range of $\approx 6.4^{\circ}$ (Figs. 1 and 2 ). On side $B$, the $\theta-2 \theta$ and rocking curves XRDs show 200- and 103-plane orientation in the range of $3.1^{\circ}$ and $3.0^{\circ}$, respectively.

We found that our samples had different preferred orientations within $1 \mathrm{~mm}$, but with high intensities, suggesting that the individual large grains are well oriented, but with deviations among them. This result is similar to that from single crystals. One important difference is that, in our study, we looked at all the faces of the specimen, which is not usually the case for studies reported in literature $[9,10]$. It may be that differences, on a micrometer $(\mu \mathrm{m})$ scale, do exist in single crystals as well and what has been reported is simply an average FWHM.

We do observe some inhomogeneity in the samples, which may be caused by other phases that are present. This is common for melt-processed 123 materials, because they are cooled from above the peritectic temperature. The domain, grain, and defect phase dimensions were measured by optical microscopy (Fig. 3). The domains of the MTG sample were of $\approx 500 \mu \mathrm{m}$, and the 211 phase (in the shape of rods) in the samples was unoriented, randomly distributed, and $\approx 10-15 \mu \mathrm{m}$ long and $5 \mu \mathrm{m}$ wide (Fig. 3a). However, CuO inclusions were quite rare $(<1 \%)$ and predominately found at domain edges, near defects and/or impurities. The size of the $\mathrm{CuO}$ inclusions depended greatly on the crack spacing (some cracks and pores were present in most of these materials, whereas SSR samples were usually somewhat porous, as 
indicated by a density that was lower than the expected ideal one), but most were $\approx 5 \mu \mathrm{m}$.

The QMGP sample texture was similar to that of the MTG sample: however, the domains were a bit larger $(600 \mu \mathrm{m})$. For the QMGP sample, slightly fewer 211-phase particles were observed and they were smaller, i.e., on the order of 5-10 $\mu \mathrm{m}$ long and $3 \mu \mathrm{m}$ wide (Fig. $3 \mathrm{~b}$ ). These results are similar to those reported by Murakami et al. [11], who observed that the average size of a 211 particle was $\approx 2 \mu \mathrm{m}$ in diameter. In the QMGP sample, the $\mathrm{CuO}$ particles were rare and found in the same places (cracks) where they were observed in the MTG sample. From these results, we can suggest that, in the MTG samples, the 211 phase solidified first in the 123 matrix and then the liquid CuO moved into the thermal-gradient cracks to solidify later.

Both melt-processed samples exhibited a highly continuous matrix of 123 phase, whereas, in contrast, the conventionally prepared sample exhibited a somewhat porous matrix of 123 phase. The size of the 123 grains was on the order of $\approx 5-6 \mu \mathrm{m}$ (Fig. 3c).

SQUID magnetic measurements have been used to determine superconducting properties such as $T_{c}$ and $J_{c}$. The $T_{c}$ values of the QMGP, MTG, and conventional pellets were $92,91.5$, and $91 \mathrm{~K}$, respectively, as derived from magnetization data measured during the warming runs after cooling the samples in a zero field. The $\mathrm{J}_{\mathrm{c}}$ values at $77 \mathrm{~K}$ were determined from the width of the hysteresis loops at an applied field of $2 \mathrm{kG}$. Figure 4 shows the SQUID hysteresis loop measured at $77 \mathrm{~K}$ for the QMGP sample.

For the melt-textured bulk material, $J_{c}$ values in the range of $4000-17,000$ $\mathrm{A} / \mathrm{cm}^{2}$ at $\mathrm{H}=0$, and $77 \mathrm{~K}$ have been reported $[8,12]$. The QMGP sample in our 
study exhibited $J_{c}$ values of $\approx 4500 \mathrm{~A} / \mathrm{cm}^{2}$ at $\mathrm{H}=2000 \mathrm{G}$, and $77 \mathrm{~K}$. The $J_{c}$ of the MTG sample was $\approx 1100 \mathrm{~A} / \mathrm{cm}^{2}$ at $77 \mathrm{~K}(\mathrm{H}=2000 \mathrm{G})$. The slightly higher $\mathrm{J}_{\mathrm{c}}$ of the GMGP sample was probably due to fewer and smaller 211 particles embedded in the 123 matrix.

For all three pellets, the $J_{c}$ values were calculated from hysteresis loops at $77 \mathrm{~K}$, with a modified version of Bean's $\mathrm{J}_{\mathrm{c}}$ model [13], and the widely accepted formula [1 1 ] for a square sample of side-length $d$ given by

$$
\mathrm{J}_{\mathrm{c}}=30 \frac{\Delta \mathrm{M}}{\mathrm{d}} \text { (Gauss). }
$$

The high $J_{c}$ of the melt-textured samples is thought to be caused by single-crystallike properties such as large grain size with excellent preferred orientation within each large grain.

\section{SUMMARY}

In this paper, we compared the orientation and functional properties of QMGP, MTG, and conventionally processed (SSR) bulk 123 superconductors. The melt-processed samples exhibited preferred orientation characteristics in each grain, with a narrow distribution of orientation (rocking curve $\mathrm{XRD} \approx 3.2^{\circ}$ wide) comparable to that in single crystals $\left(8-10^{\circ}\right)$. The preferred orientation of each grain is excellent in all directions even though the direction of the preferred orientation changes slightly from grain to grain. Such a detailed study of the preferred orientational fluctuations in all directions has not been reported in the past for QMGP samples $[8,11,12]$. The XRD peaks are narrow and intense because, in our samples, the domains are large $(\approx 500 \mu \mathrm{m})$. The QMGP has the highest $J_{c}$ of the three bulk samples and it is $\approx 4500 \mathrm{~A} / \mathrm{cm}^{2}$, at 
$\mathrm{H}=2000 \mathrm{G}$ and $\mathrm{T}=77 \mathrm{~K}$, most probably because of fewer and smaller particles of 211 phase in the 123 matrix, as compared to the MTG sample.

\section{ACKNOWLEDGMENTS}

The authors thank Dr. Mamoun Muhammed for the use of the X-ray diffractometer and Dr. Hannes Medelius and Prof. David Rowcliffe for the use of optical microscopy and photography equipment. Work at the Royal Institute of Technology is supported by the Swedish Funding Agencies NUTEK and NFR. Work at Argonne National Laboratory is supported by the U.S. Department of Energy, Energy Efficiency and Renewable Energy, as part of a program to develop electric power technology, under Contract W-31-109-Eng-38.

\section{REFERENCES}

1. R. J. Cava, Scientific American, Aug. 1990, pp. 24-31.

2. S. Jin, T. H. Tiefel, R. C. Sherwood, R. B. van Dover, M. E. Davis, G. W. Kammlott, and R. A. Fastnacht, Appl. Phys. Lett. 37, 7850 (1988). :

3. J. Huber, "Superconducting Thin Films of $\mathrm{YBa}_{2} \mathrm{Cu}_{3} \mathrm{O}_{7-\mathrm{x}}$," Ph.D. Thesis, Royal Institute of Technology, Stockholm, Sweden, 1993.

4. M. A. Rodriguez, R. L. Snyder, B. J. Chen, D. P. Matheis, S. T. Misture, V. D. Frechette, G. Zorn, and B. Seebacher, Physica C 206, 43 (1993).

5. S. J. Golden, T. Yamashita, A. Bhargava, J. C. Barry, and I. D. R. Mackinnon, Physica C 221, 85 (1994).

6. B. J. Chen, M. A. Rodriguez, S. T. Misture and R. L. Snyder, Physica C 198, 118 (1992). 


\section{$-9$}

7. U. Blachandran, R. B. Poeppel, J. E. Emerson, S. A. Johnson, M. T. Lanagan, C. A. Youngdahl, D. Shi, K. C. Goretta, and N. G. Eror, Mater. Lett. 8, 454 (1989).

8. T. D. Askenova, P. V. Bratukhin, I. V. Zakhartchenko, and S. V. Shavkin, Sverkhprovodimost: Flz., Khim., Tekh. 1990, 3 (8, pt. 2) 1858-64. (Russian).

9. L. Zugang, W. Xuefeng, S. Linjing, J. Xichun, L. Min, X. Hongwu, Y. Nanru, J. Mater. Sci. Lett., 9, 39-41 (1990).

10. Ś. Jin, T. H. Tiefel, R. C. Sherwood, M. E. Davis, R. B. van Dover, G. W. Kammlott, R. A. Fastnacht, and H. D. Keith, Appl. Phys. Lett. 52, 2074 (1988).

11. M. Murakami and N. Koyama, Mater. Res. Symp. 156, 374 (1989).

12. D. Shi, M. M. Fang, J. Akujleze, M. Xu, J. G. Chen, and C. Segre, Appl. Phys. Lett. 57, 2606-2608 (1990).

13. C. P. Bean, Phys. Rev. Lett. 8, 250 (1962). 


\section{Figure captions}

Fig. 1. Four largest $\theta-2 \theta$ XRD spectrums of the MTG sample. Each side has different large peaks, suggesting different preferred orientations.

Fig. 2. Rocking curve XRD spectrums of three sides of MTG $\mathrm{YBa}_{2} \mathrm{Cu}_{3} \mathrm{O}_{7-\mathrm{X}}$ sample. Each side has narrower (FWHM $\cong 3.2-6.4^{\circ}$ ) curves than are found in most single crystals $\left(8-10^{\circ}\right)$.

Fig. 3. Optical photomicrographs of (a) MTG, (b) GMGP, and (c) solid-state sintered $\mathrm{YBa}_{2} \mathrm{Cu}_{3} \mathrm{O}_{7-\mathrm{x}}$ bulk pellets. Note that fewer and smaller 211 (light colored) particles are present in the QMGP sample.

Fig. 4. SQUID hysteresis loop at $77 \mathrm{~K}$ for $\mathrm{QMGP} \mathrm{YBa}_{2} \mathrm{Cu}_{3} \mathrm{O}_{7-\mathrm{x}}$ sample. 

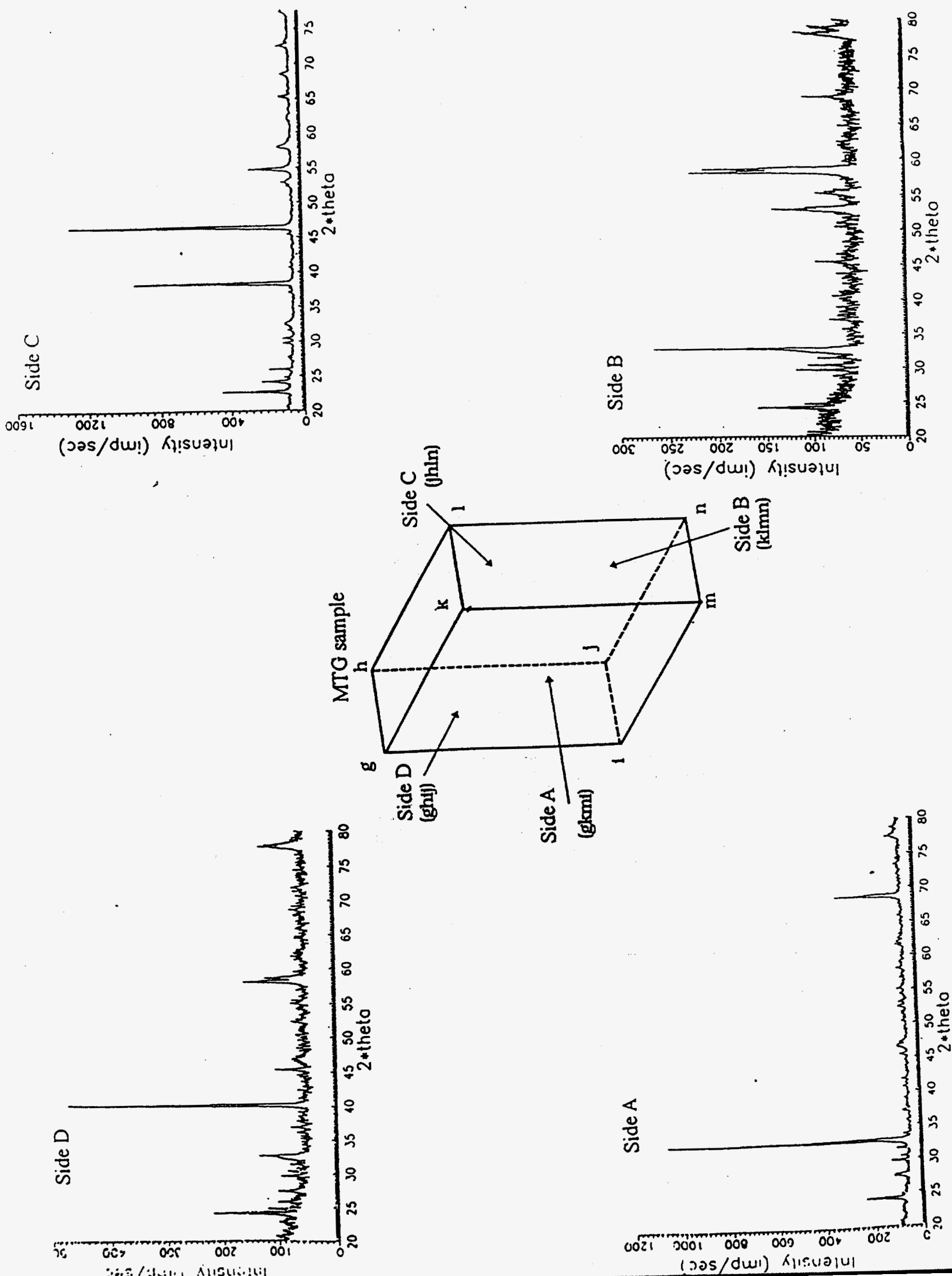

语可 


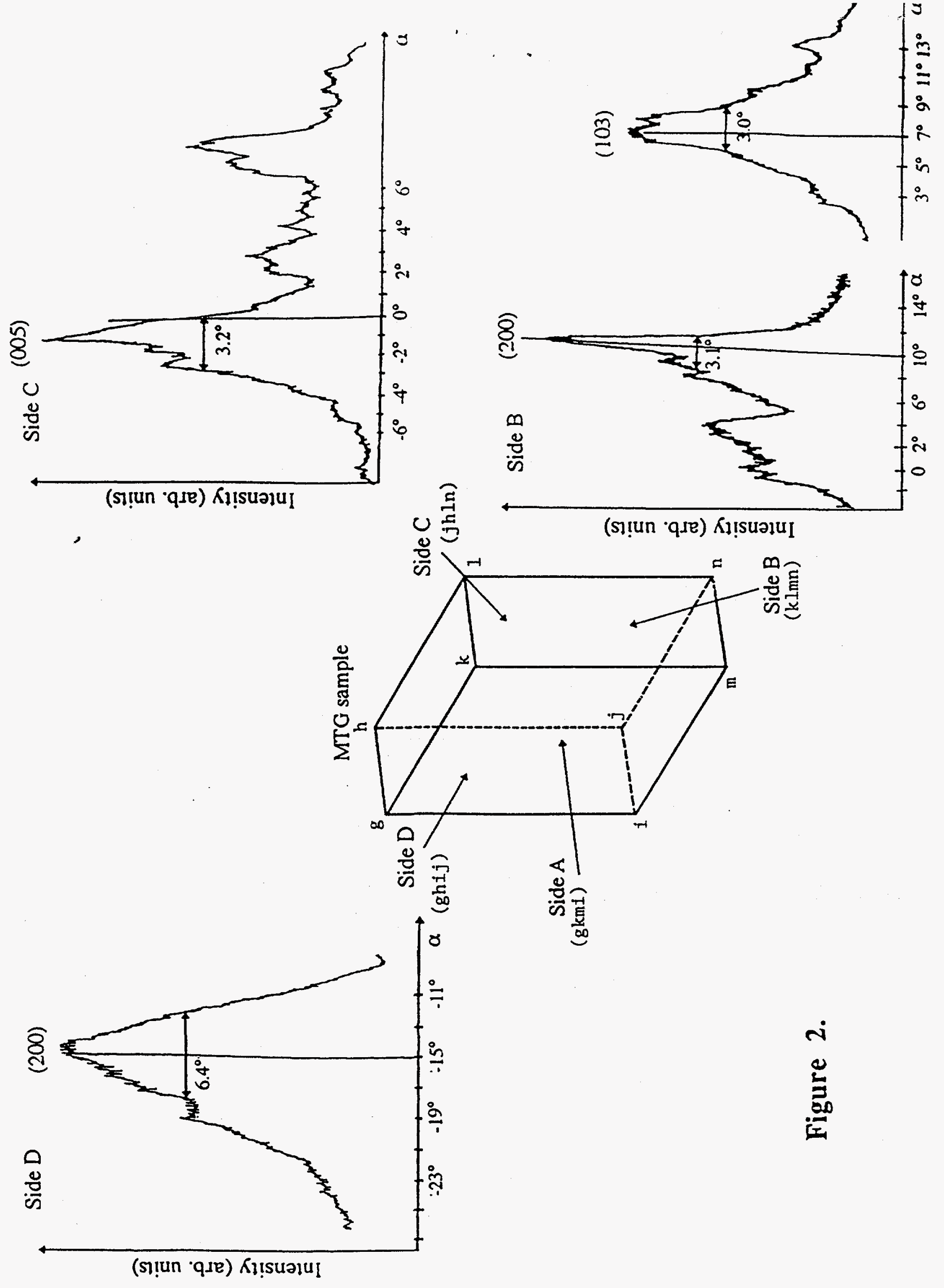



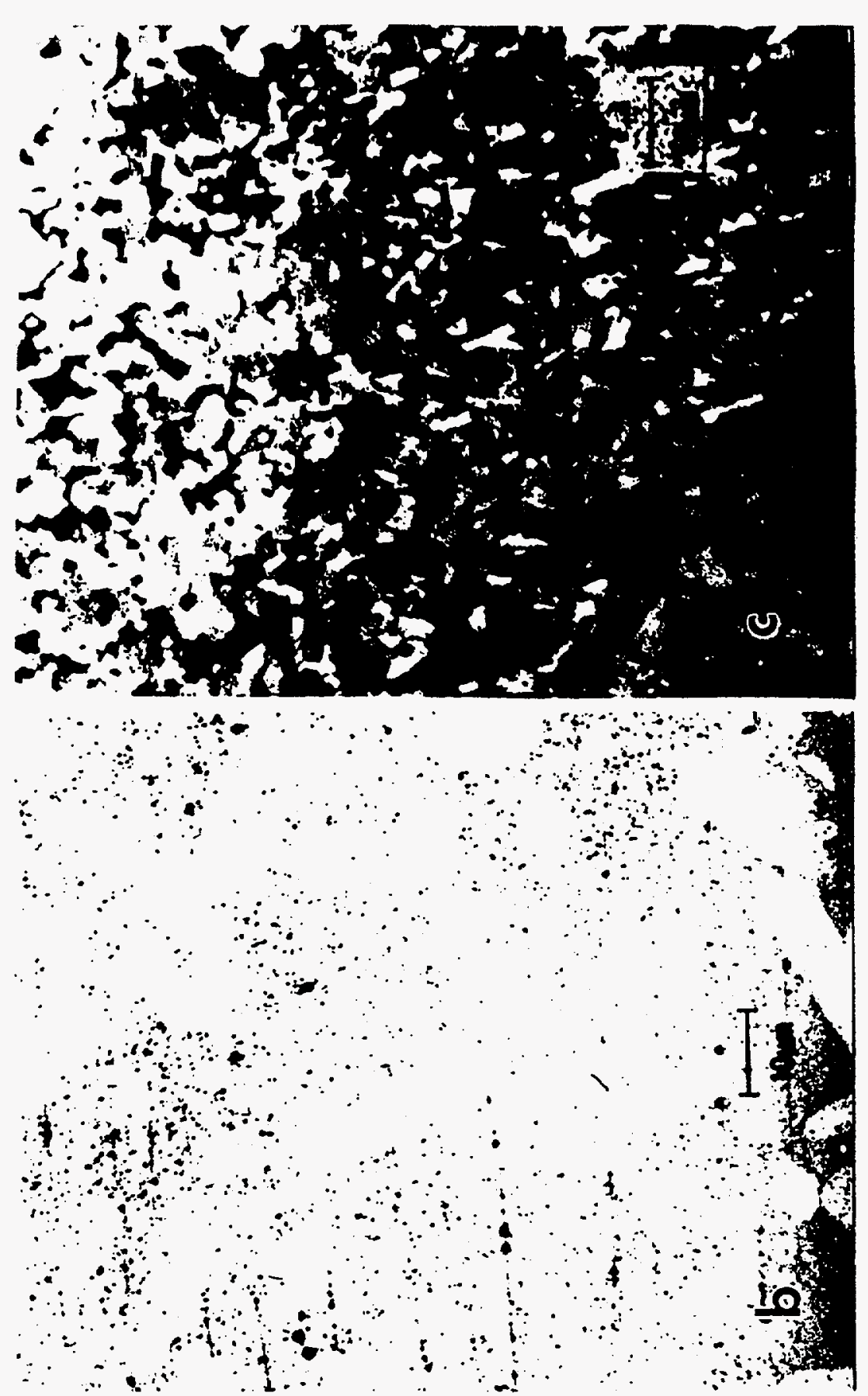

क

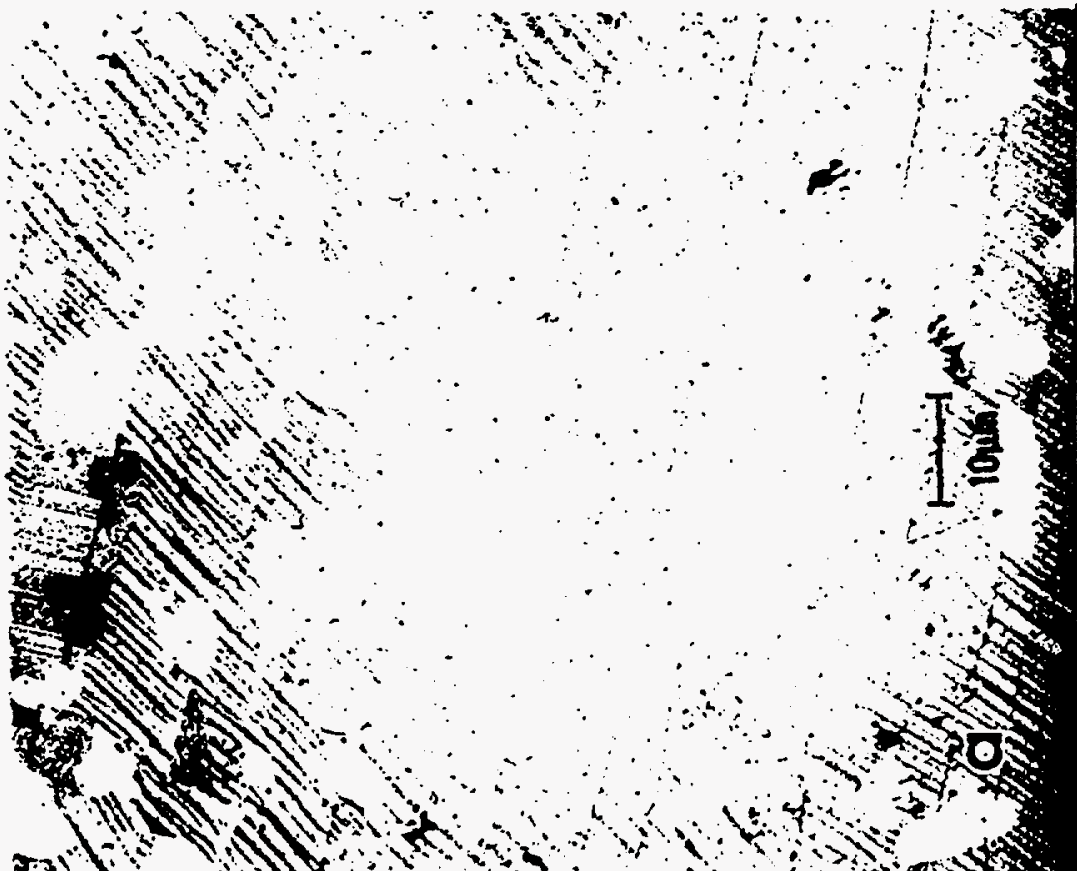




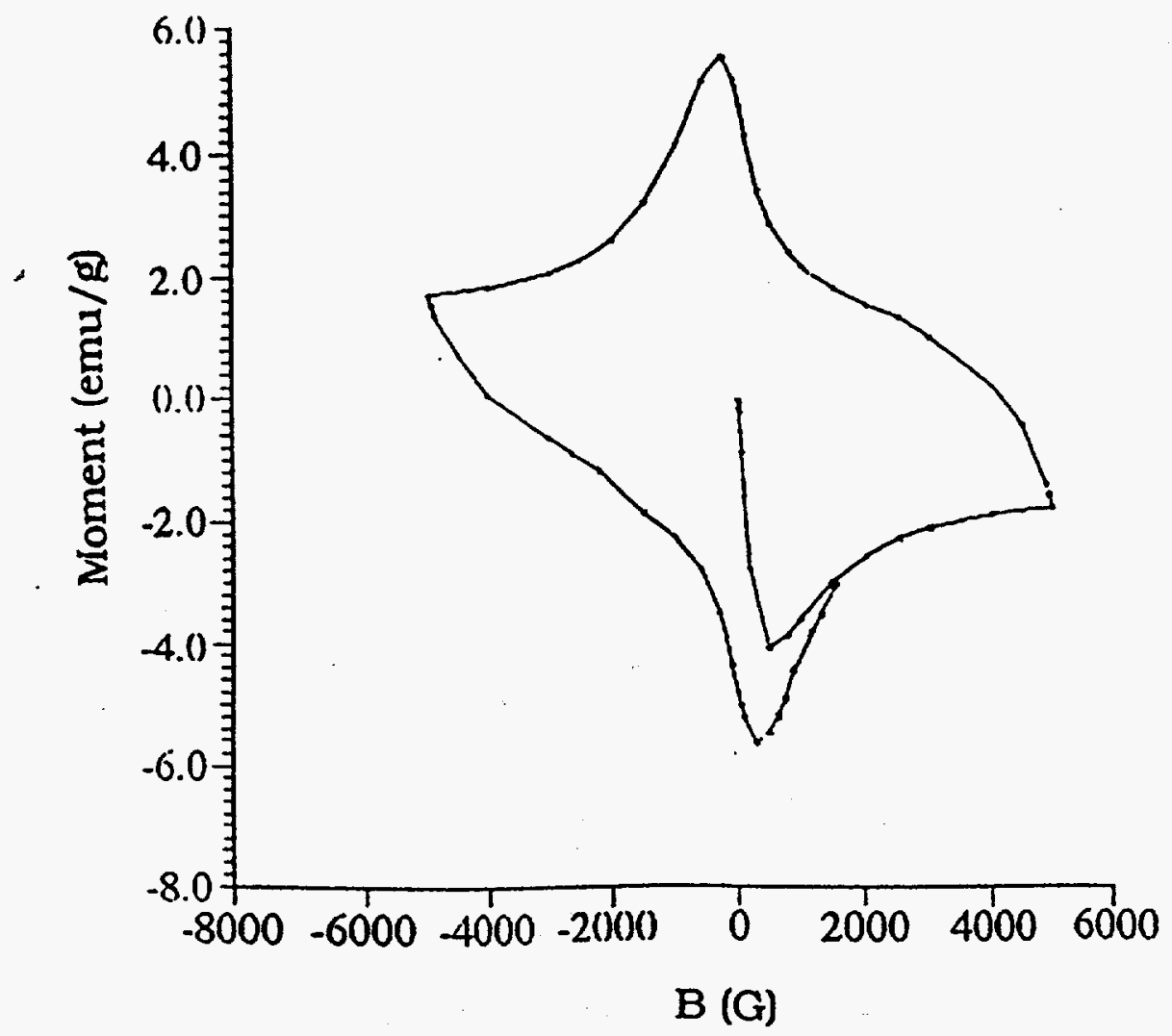

Figure 4. 